\title{
Trajetórias de mulheres na ciência: "ser cientista" e "ser mulher"
}

\section{Paths of women in science: "being a scientist" and "being a woman"}

\author{
Fabiane Ferreira da Silva ${ }^{1}$. Paula Regina Costa Ribeiro ${ }^{2}$
}

Resumo: O artigo aborda a trajetória acadêmica e profissional de mulheres na ciência. A produção de entrevistas com mulheres cientistas atuantes em universidades públicas e numa instituição de pesquisa do Rio Grande do Sul constitui o corpus de análise deste estudo. Na análise, chamamos a atenção para o poder que atravessa as relações sociais constituindo identidades e diferenças que geram preconceitos de gênero. Nas narrativas, emergiu a negação do preconceito, o reconhecimento de "brincadeiras" sexistas que não são percebidas como preconceito, e situações explícitas de preconceito de gênero. Outro aspecto evidenciado refere-se à necessidade de conciliar a profissão com as responsabilidades familiares, que implicou jornadas parciais de trabalho, o adiamento ou recusa da maternidade. No artigo, argumentamos que a trajetória das entrevistadas na ciência foi e é construída em um ambiente baseado em valores e padrões masculinos, que restringem, dificultam e direcionam a participação das mulheres na ciência.

Palavras-chave: Mulher. Ciência. Gênero. Universidade. Trajetória acadêmica.

\begin{abstract}
The article discusses the academic and professional history of women in science. The production of interviews with women scientists working in public universities and in a research institution in Rio Grande do Sul is the corpus of analysis in this study. In the analysis we draw attention to the power that crosses social relations constituting identities and differences that generate gender bias. In the narratives the denial of bias emerged - the recognition of sexist "jokes" that are not defined as bias and situations perceived as explicit gender bias. Another aspect refers to the need for reconciling professional life with family responsibilities, which resulted in part time work, and the postponement or refusal of motherhood. In the study we argue that the history of interviewees in science was and is built in an environment based in male values and patterns that restrict, impede and direct the participation of women in science.
\end{abstract}

Keywords: Women. Science. Gender. University. Academic career.

\footnotetext{
${ }^{1}$ Universidade Federal do Pampa (UNIPAMPA), campus Uruguaiana, BR $472 \mathrm{~km} \mathrm{585,} \mathrm{Caixa} \mathrm{Postal} \mathrm{118,} \mathrm{CEP}$ 97500-701, Uruguaiana, RS, Brasil. E-mail: fabianesilva@unipampa.edu.br

${ }^{2}$ Instituto de Educação, Universidade Federal do Rio Grande (FURG), Rio Grande, RS, Brasil.
} 


\section{Considerações iniciais}

O feminismo contemporâneo contribuiu para transformar a posição das mulheres na ciência, pois, nas últimas décadas, testemunhamos avanços significativos no que diz respeito à inserção e à participação das mulheres no campo científico. Atualmente, é possível perceber o número expressivo de mulheres em muitas universidades e instituições de pesquisa. Contudo, verifica-se que essa participação vem ocorrendo de modo dicotimizado, uma vez que as mulheres tendem a se concentrar em determinadas áreas, tais como: Psicologia, Linguística, Nutrição, Serviço Social, Fonoaudiologia, Economia Doméstica e Enfermagem, os chamados "guetos femininos" (FELÍCIO, 2010).

Outra questão que vem sendo muito discutida refere-se ao fato de que as mulheres não avançam na carreira na mesma proporção que os homens. A ascensão profissional pode ser observada, por exemplo, na participação em cargos administrativos, no nível mais elevado da carreira universitária (professor(a) titular), no recebimento de bolsa de Produtividade em Pesquisa (PQ) do CNPq, ou na participação em comitês de assessoramento das agências de fomento. Tomando como referência o número de bolsas PQ do CNPq por categoria e sexo do bolsista (BRASIL, 2012), dados de 2010 mostram que as mulheres representam apenas $34,8 \%$ do número de bolsistas, sendo que o número de mulheres decresce conforme aumenta a hierarquia acadêmica.

Como parte do fenômeno denominado de "teto de vidro", a existência de barreiras ao acesso a níveis de maior hierarquia e prestígio compromete, geralmente, as mulheres na construção da sua carreira na ciência. Portanto, mesmo que atualmente a participação das mulheres na ciência seja equitativa do ponto de vista numérico, a hierarquia acadêmica vai estar ocupada, sobretudo, por homens, independentemente da área do conhecimento.

A que se devem essas situações de desigualdade na ciência? Quais mecanismos têm dificultado a participação das mulheres na ciência e o acesso delas às posições de destaque? Por que as mulheres não ascendem na carreira da mesma forma que os homens? Para Estébanez (2004), a resposta tradicional "meritocrática" indicaria que os avanços são correspondentes ao nível de desempenho acadêmico, uma vez que os sistemas de avaliação estão estritamente relacionados com a produção científica dos(as) pesquisadores(as), que, no contexto acadêmico, é um dos indicadores da medição da qualidade e capacidade profissional. Nesse contexto, algumas questões se colocam: seriam as mulheres menos "produtivas" do que os homens ou estariam solicitando menos bolsas ao CNPq ou a outros órgãos de fomento? A resposta para essas questões não é assim tão simples quanto as estatísticas parecem indicar. Sabe-se, com base em algumas pesquisas qualitativas (CABRAL, 2006; LIMA, 2008; SOU$\mathrm{ZA}, 2003)$ que procuram discutir as trajetórias e estratégias profissionais das mulheres na ciência, que elas tiveram/têm de "vencer" muitas dificuldades e barreiras na construção de suas carreiras. Conforme argumenta Velho:

\footnotetext{
${ }^{3}$ A expressão "teto de vidro" é utilizada como metáfora que significa a invisibilidade dos obstáculos que limitam e dificultam a ascensão das mulheres na carreira profissional, uma vez que não existem barreiras formais que justifiquem o fato de as mulheres não conseguirem ascender profissionalmente na mesma proporção que os homens. Schiebinger (2001) discute o conceito de "teto de vidro".
} 
Uma vez feita a opção pela carreira científica, a mulher se depara com o conflito da maternidade, da atenção e obrigação com a família vis-a-vis as exigências da vida acadêmica. Algumas sucumbem e optam pela família, outras, pela academia, e um número decide combinar as duas. Sobre essas últimas, não é necessário dizer quanto têm que se desdobrar para dar conta não apenas das tarefas múltiplas, mas também para conviver com a consciência duplamente culposa: por não se dedicar mais aos filhos e por não ser tão produtiva quanto se esperaria (ou gostaria). (VELHO, 2006, p. xv)

A trajetória das mulheres na ciência é constituída numa cultura baseada no "modelo masculino de carreira" (VELHO, 2006) que envolve compromissos de tempo integral para o trabalho, produtividade em pesquisa, relações academicamente competitivas e a valorização de características masculinas que, em certa medida, dificultam, restringem e direcionam a participação das mulheres nesse contexto. Nessa perspectiva, concordamos com Tabak (2002, p. 49), ao argumentar "que é muito mais difícil para a mulher seguir uma carreira científica numa sociedade ainda de caráter patriarcal e em que as instituições sociais capazes de facilitar o trabalho da mulher ainda são uma aspiração a conquistar.".

Considerando tais questões, buscamos conhecer a trajetória acadêmica e profissional de um grupo de mulheres cientistas, a partir da realização de entrevistas. Para compreender as trajetórias dessas mulheres, nos valemos da noção de trajetória discutida por Bourdieu (2006, p. 189), "como série de posições sucessivamente ocupadas por um mesmo agente (ou um mesmo grupo) num espaço que é ele próprio um devir, estando sujeito a incessantes transformações". Nesse sentido, Bourdieu (2006), nos auxilia a pensar a trajetória não como uma narrativa coerente de uma sequência de acontecimentos lineares, que tem um começo, um meio e um fim, mas sim, como uma narrativa que constrói e ressignifica percursos, acontecimentos, experiências, representações de si e dos outros, que se desviam e se deslocam a todo o momento a partir dos lugares sociais e culturais ocupados pelos sujeitos. Desse modo, entendemos que as narrativas das entrevistadas sobre suas trajetórias de vida como mulheres e cientistas são construções sobre momentos passados, histórias e memórias, sobre experiências individuais e coletivas, compartilhadas com as pessoas pertencentes a uma mesma geração.

As experiências vividas pelas entrevistadas estão implicadas na constituição delas como cientistas e mulheres de determinados tipos. Nessa direção, ao analisarmos as experiências dessas mulheres na ciência, buscamos "explorar como se estabelece a diferença [e a identidade], como ela opera, como e de que forma ela constitui sujeitos que veem e agem no mundo" (SCOTT, 1999, p. 26). Ao historicizarmos suas experiências, ao narrarmos suas histórias, buscamos romper com proposições universalizantes, deterministas e essencialistas das identidades femininas, na direção de pensar sobre o caráter plural, histórico, mutável e construído das identidades - de gênero, classe social, étnica/racial, profissional, entre outras. Conforme propõe Scott (1999, p. 27):

[...] precisamos dar conta dos processos históricos que, através do discurso, posicionam sujeitos e produzem experiências. Não são os indivíduos que têm experiência, mas os sujeitos é que são constituí- 
dos através da experiência. A experiência, de acordo com essa definição, torna-se, não a origem da nossa explicação, não a evidência autorizada (porque vista ou sentida) que fundamenta o conhecimento, mas sim aquilo que buscamos explicar, aquilo sobre o qual se produz conhecimento. Pensar a experiência dessa forma é historicizá-la, assim como as identidades que ela produz.

Nessa perspectiva, é preciso destacar a qualidade produtiva do discurso, já que os sujeitos são constituídos discursivamente em meio a relações de poder. Um poder que, segundo Foucault (2006), é constituído por muitas relações de força, que está disseminado pela sociedade, é capilar, difuso, algo que se exerce e funciona em rede e faz dos indivíduos sujeitos. De acordo com Foucault (1995, p. 235), ser sujeito significa estar "sujeito a alguém pelo controle e dependência, e preso à sua própria identidade por uma consciência ou autoconhecimento. Ambos sugerem uma forma de poder que subjuga e torna sujeito". Os sujeitos são fabricações discursivas, tanto a partir dos processos de objetivação, que os constituem como corpos dóceis, úteis e produtivos; quanto dos processos de subjetivação, que os tornam sujeitos de determinadas identidades.

Para Silva (2005), a identidade pressupõe a diferença, ou seja, são produzidas social e culturalmente de modo relacional em meio a relações de poder. $\mathrm{O}$ entendimento de que as identidades são construídas na relação com outras identidades e com as diferenças pressupõe a formação de oposições binárias, em que um polo é considerado positivo e o outro negativo, sendo o primeiro par a referência de todo o discurso legitimado. Na lógica das oposições binárias, que estruturam o pensamento moderno, o homem é a referência e a mulher é apresentada como o "outro", o oposto do homem. Na ciência, a mulher é esse "outro", já que, desde o nascimento da ciência moderna, o sujeito do conhecimento tem sido o homem e, portanto, as características e habilidades necessárias e valorizadas para fazer ciência são as ditas masculinas.

A ciência, neste estudo, é entendida como uma narrativa, uma invenção social e histórica estabelecida em profundas e intrincadas redes de poder, que institui procedimentos, métodos, saberes e "verdades" e, ao mesmo tempo, determina quem pode fazer ciência e sentirse cientista (HENNING, 2008).

$\mathrm{Na}$ continuidade deste texto, num primeiro momento, apresentamos o referencial metodológico que subsidia esta pesquisa e a estratégia de produção e análise dos "dados". Num segundo momento, tecemos discussões sobre o preconceito de gênero na ciência. Finalizamos a discussão problematizando a necessidade de conciliar as exigências da profissão com as responsabilidades familiares.

\section{Caminhos teórico-metodológicos}

Este estudo ancora-se metodologicamente na investigação narrativa a partir das contribuições de Larrosa (1996, 2004) e Connelly e Clandinin (1995). Na perspectiva teórica desses autores, passamos a compreender a narrativa como formações discursivas por meio das quais os sujeitos vão dando sentido aos percursos vividos. Além disso, conforme destaca 
Larrosa (1996), é no processo narrativo que os sujeitos passam a construir a sua história, a dar sentido a quem são e a quem são os outros, constituindo, assim, suas identidades.

De acordo com Connelly e Clandinin (1995), diversos instrumentos podem ser utilizados para a "coleta dos dados", tais como: registros em diário, entrevistas, cartas, escritos autobiográficos e biográficos, documentos, fotografias, entre outros. Neste estudo optamos pela realização de entrevistas individuais, compreendidas como "eventos discursivos complexos, forjados não só pela dupla entrevistador/entrevistado, mas também pelas imagens, representações, expectativas que circulam - de parte a parte - no momento e situação de realização das mesmas e, posteriormente, de sua escuta e análise" (SILVEIRA, 2007, p. 118). A metodologia de análise das entrevistas centra-se na análise do discurso a partir de Michel Foucault (2008).

Com a realização das entrevistas, buscamos conhecer a trajetória acadêmica e profissional de seis mulheres cientistas que atuam em universidades federais e numa instituição de pesquisa do Rio Grande do Sul, e, desse modo, identificar, nas trajetórias narradas: preconceitos, discriminações, conflitos, dificuldades, conquistas, relações entre trabalho e vida familiar, entre outros aspectos.

As participantes da pesquisa são mulheres que produzem conhecimentos em diferentes áreas da ciência, sendo uma da área da Farmácia, duas de Ciências Biológicas, duas da Física e a outra da Engenharia de Computação; possuem mais de 15 anos de experiência profissional, desenvolvem projetos de pesquisa financiados por diversas agências, e atuam na graduação e em programas de pós-graduação. São cientistas que se encontram em diferentes estágios na carreira, sendo uma delas pesquisadora aposentada. Das seis cientistas, duas possuem bolsa de Produtividade em Pesquisa e uma possui bolsa de Produtividade em Desenvolvimento Tecnológico e Extensão Inovadora. São mulheres com diferenças de idades (na faixa etária de quarenta a 75 anos), posições na carreira, linhas de pesquisa, experiências e trajetórias.

Ao longo das entrevistas, as cientistas reconstituíram: as vivências na graduação e na pós-graduação, as situações de preconceito e discriminação, os desafios e as dificuldades da profissão, a competitividade na pesquisa, as exigências da publicação, a experiência da maternidade, a conciliação das identidades de mãe e cientista... Assim, analisamos, nas narrativas das participantes, as experiências por elas escolhidas para dar sentido aos percursos vividos.

Com o objetivo de analisar as trajetórias acadêmicas e profissionais, lembramos que a trajetória de cada cientista é uma construção singular, específica, individual, portanto, não pretendemos simplesmente comparar experiências nem tampouco tecer generalizações. Entretanto, convém sublinhar que, embora a história de vida de cada uma delas se constitua como uma história individual, ela também é coletiva, pois se trata de uma história vivida coletivamente, localizada num determinado contexto cultural, histórico e social. Nesse sentido, buscamos encontrar pontos de encontro nas trajetórias de vida das entrevistadas, ou seja, as continuidades que revelam experiências semelhantes, ainda que vividas de formas distintas por cada uma das cientistas. Assim, olhamos para as continuidades discursivas, mas também para as descontinuidades, para os discursos que não são recorrentes. Em uma perspectiva foucaultiana, tratamos os discursos "como práticas que formam sistematicamente os objetos de que falam" (FOUCAULT, 2008, p. 55), ou seja, como implicados na constituição dos corpos, dos sujeitos, das identidades... Nas trajetórias narradas, emergiram os discursos - da família, da maternidade, da ciência, da biologia, do feminino e do masculino... - que estiveram 
Silva, F. F.; Ribeiro, P. R. C.

implicados na constituição das entrevistadas como mulheres e cientistas. Considerando tais discursos, estabelecemos as seguintes categorias de análise: preconceitos de gênero na ciência e a necessidade de conciliar a profissão com as responsabilidades familiares.

\section{Preconceitos de gênero na ciência: discursos "(in)visíveis”}

A ciência como um construto humano não está isenta das múltiplas formas de preconceito e discriminação de gênero, etnia/raça, classe social, geração, nacionalidade, entre outros. Centraremos a discussão no preconceito de gênero constituído nas relações sociais no contexto da ciência. De modo geral, as relações de gênero que se estabelecem no cotidiano das universidades e instituições de pesquisa, espaços onde se produz a ciência, são atravessadas por relações de poder que (re)produzem identidades e diferenças. Nesse sentido, consideramos importante discutir como as identidades são instituídas nas práticas sociais por meio do processo de produção da diferença, que pode gerar preconceitos de gênero. Neste texto, tomamos por preconceito de gênero os discursos e as práticas sociais que inferiorizam ou excluem as mulheres em função do seu sexo.

No contexto desta discussão, é importante destacar que o preconceito não afeta todas as mulheres por igual, muitas vezes, opera de forma sutil e velada, bem como de forma explícita. Estas diferentes facetas do preconceito de gênero foram percebidas nas experiências narradas.

Inicialmente, convém sublinhar que as cientistas da área das Ciências Biológicas afirmaram que nunca sentiram preconceito ou discriminação por serem mulheres, atribuindo tal fato à área em que estão inseridas, que apresenta equivalência no número de mulheres e homens, bem como à adoção de uma postura respeitadora diante de seus pares.

Eu nunca senti preconceito. Eu acho que é tudo uma questão de como tu te coloca. (Bildi)

Eu nunca me senti prejudicada pelo fato de ser mulher, nunca. (Carolina)

Não, justamente por ser a maioria mulher acho que não tinha, eu não senti, pelo menos. Aqui [universidade em que atua] eu sou extremamente respeitada, a maioria dos meus colegas com os quais eu faço colaboração são homens, e eu gosto de trabalhar com homens, eu sempre me senti muito respeitada trabalhando com homens. Nunca tive problema. Não me senti, em nenbum momento, discriminada. (Mariana)

Entretanto, reconheceram a existência de situações de cunho discriminatório e preconceituoso que são tomadas como "brincadeiras" e que, justamente por isso, não incomodam, não são levadas a sério.

XX e XY? Tem, mas en levo pro lado da brincadeira, porque se não fosse brincadeira eu ia brigar. Existe assim ó: eu chamo pra me socorrer num problema de computador que não é o meu forte e tem uns colegas que são. Ai eles 
chegam, arrumam, geralmente coisas muito simples e muito rápidas e ai eles dizem assim: "Não te preocupa, isso é o teu XX que precisa do meu XY.". Isso existe. Mas te dizer assim de não ser respeitada, um projeto grande tu não ser chamada ou tu ser chamada e tu ver que primeiro os homens são... Não, isso nunca aconteceu. Brincadeira tem. A gente tá reunido, a maioria das minhas alunas são mulheres, e aí, por exemplo, abre a porta... Agora tu tá falando e tu tá me fazendo pensar e geralmente é uma pessoa que faz isso, [risos], geralmente é um colega que abre a porta e diz assim: "Já sei, com certeza estão fofocando?". Por quê? Porque é um bando de mulher que tá ali junto. Então realmente às vezes existe isso. Mas não é uma coisa que me incomode, eu acho isso tão nada a ver, não dou bola mesmo. (Bildi)

Ao analisarmos a narrativa da Bildi, percebemos que ela descreve algumas das situações cotidianas envolvidas com a produção das identidades e diferenças. Essa narrativa nos possibilita pensar nas práticas cotidianas que se estabelecem socialmente a partir de concepções "essencialistas" das identidades baseadas em argumentos biológicos que promovem preconceito de gênero, que, frequentemente, não são percebidos pelos sujeitos envolvidos. Entretanto, conforme argumenta Silva (2005), mesmo que aparentemente esses processos de diferenciação estejam baseados no discurso biológico,

[...] as tentativas de fixação da identidade que apelam para a natureza não são menos culturais. Todos os essencialismos são, assim culturais. [...] nascem do movimento de fixação que caracteriza o processo de produção da identidade e da diferença. (SILVA, 2005, p. 86)

A produção das identidades, neste caso, de gênero ${ }^{4}$, está sempre implicada em fixar, classificar, separar, hierarquizar, instituir o feminino e o masculino, e, nesse processo, algumas características e habilidades são mais valorizadas do que outras. Nessa perspectiva, entendemos que determinadas situações, muitas vezes banalizadas e naturalizadas, precisam ser alvo da nossa atenção. Precisamos problematizar as concepções essencialistas que naturalizam as mulheres em uma falta de condições cognitivas que as inferioriza. $O$ preconceito de gênero, como produto social, cultural e histórico, que institui e determina constantemente uma imagem negativa e inferiorizada das mulheres, nem sempre se dá de forma explícita; muitas vezes, ele se dá de forma velada, sutil, e aí residem, justamente, sua força e eficácia. Conforme observa Schiebinger (2001, p. 113),

[...] ainda se encontram exemplos de sexismo ostensivo hoje em dia, mas com muito menos frequência que no passado. Mais interessantes são os preconceitos contra as mulheres - muitas vezes sem intenção - que persistem entre pessoas bem intencionadas.

\footnotetext{
${ }^{4}$ Identidade de gênero refere-se às distintas formas com que os sujeitos se identificam, social e historicamente, como masculinos e femininos (LOURO, 2004).
} 
Silva, F. F.; Ribeiro, P. R. C.

Por outro lado, é interessante problematizar o entendimento de que a existência de preconceito e discriminação de gênero se dá em função da postura que a mulher adota no ambiente de trabalho. Tal entendimento foi percebido na narrativa da Carolina:

Depende da mulher, quer dizer, se a mulher se coloca num papel estritamente feminino, e tem mulheres que geneticamente elas são assim. (Carolina)

Quando indagada sobre o que seria “estritamente feminino", ela respondeu:

Ah, delicada, sensivel, suscetivel, chorona, essa coisa toda. Eu tinha uma colega que quando tinha um problema ela chorava. Ela me dava uma irritação que en tinha que me controlar pra não sacudir ela. E eu diz̨ia pra ela assim: Tu estás aqui ocupando o lugar de um homem, tu não podes te dar o luxo de te comportar como uma mulher caseira, tu tens que fazer tudo o que o homem faria aqui no setor. E eu sempre agi assim. Eu nunca achei que uma coisa que um homem faz̧ia eu não podia fažer. Claro, a não ser força física. Mas em termos de resolver problemas, de buscar soluções, de fazer contatos... Então nenbum homem conseguiu me impedir de dar continuidade à minha pesquisa e à minha carreira. Até tentaram, mas não conseguiram, por quê? Porque a gente estava falando de igual pra igual. Naquele momento eu não era mulher e nem ele era homem. Eu era uma pesquisadora e ele era um pesquisador, um orientador. (Carolina)

De um modo geral, a nossa sociedade está constituída por uma série de dualismos: razão/emoção, ativo/passivo, pensamento/sentimento, objetivo/subjetivo, público/privado, mente/corpo, sujeito/objeto, cultura/natureza etc. Observando esses pares dicotômicos podemos dizer que eles são sexualizados, uma vez que o primeiro elemento do par corresponde ao masculino, enquanto o segundo ao feminino. Além disso, essas oposições binárias estabelecem hierarquias, já que o primeiro polo é sempre tomado como referência.

A ciência, como um produto cultural, social e histórico, desde o seu nascimento, foi moldada na dicotomia existente entre o masculino e o feminino na sociedade, e pelo fato de que, durante a maior parte da sua história, foi empreendida pelo representante do masculino - o homem, branco, ocidental, elitista e colonial (LÖWY, 2009). Portanto, os parâmetros para produzir uma ciência considerada legítima - neutralidade, objetividade, racionalidade e universalidade - incorporam a visão de mundo das pessoas que criaram essa ciência (LÖWY, 2009). Nesse sentido, a crítica feminista à ciência tem se ocupado em problematizar o entendimento de que a produção da ciência legítima se dá a partir dos valores associados ao masculino, dos quais as mulheres são consideradas naturalmente desprovidas.

Ao olharmos a narrativa da Carolina, percebemos que ela desvaloriza determinadas características femininas em detrimento das características masculinas, consideradas adequadas para produzir conhecimentos científicos. Para ela, a mulher, na ciência, ocupa o lugar de um homem e, portanto, não deve se comportar como "uma mulher caseira", mas deve fazer tudo o que um homem faria. Tal entendimento pressupõe uma adaptação ao "modelo mas- 
culino" de pensar e fazer ciência, que valoriza características e habilidades masculinas, dedicação em tempo integral, relações academicamente competitivas, entre outros aspectos (VELHO, 2006). A narrativa da Carolina nos leva a pensar que a constituição da sua identidade de cientista foi atravessada por esse modelo androcêntrico de ciência. Necessariamente, espera-se que as mulheres se adaptem a esse modelo, não apenas para serem consideradas cientistas, mas, também, se querem ser bem-sucedidas na carreira. Souza (2003), ao discutir a formação de mulheres cientistas, argumenta que o modelo hegemônico de ciência, marcado por um viés androcêntrico, no que se refere aos procedimentos considerados legítimos, aos objetivos e usos de produtos do conhecimento, é reproduzido na Academia, de modo que os cursos que formam cientistas estão impregnados de valores masculinos, expressos: no campo simbólico, no uso de metáforas sexuais e sexistas, na forma como os sujeitos são socializados, nos pressupostos que orientam o fazer científico.

Especialmente na Física e em alguns ramos da Engenharia, as mulheres são consideradas pessoas "fora de lugar". Muitas foram as situações de preconceito e discriminação narradas pelas cientistas da área da Física e da Engenharia de Computação. Na narrativa que se segue, podemos perceber o preconceito de gênero do orientador da Sianiak, ao se referir a uma aluna dizendo que ela tinha, e fazer licenciatura, uma profissão mais condizente com sua identidade de gênero.

Houve um caso, eu já estava fazendo mestrado, que o meu orientador de mestrado teve um ataque histérico em sala de aula e disse pra uma menina que ela tinha mesmo que fazer licenciatura porque ela nunca ia conseguir sair do bacharelado [em Fisica]. (Sianiak)

Essa narrativa apresenta elementos que nos possibilitam discutir os espaços sociais que os sujeitos devem e podem ocupar de acordo com o seu sexo, resultado de uma visão dicotômica naturalizada, que rotula razão, objetividade, raciocínio lógico como "masculinos", e sentimento, subjetividade, doação, cuidado como "femininos", e que, portanto, estão subjacentes à exclusão das mulheres de determinadas áreas científicas, tais como a Física e a Engenharia. Na hierarquização das áreas do conhecimento, o bacharelado em Física é representado como uma área mais complexa e difícil do que a licenciatura, por exigir do(a) aluno(a) mais habilidades e conhecimentos em Matemática. Portanto, é mais lógico que a mulher faça licenciatura, invista na docência, uma profissão que mais se relaciona com as características e habilidades femininas. Cabe destacar que a Física é a área que se mantém mais restrita às "incursões" das mulheres. Dados do CNPq mostram que a representatividade feminina na Física não ultrapassa a $20 \%$ (FELÍCIO, 2010). Portanto, as poucas mulheres que fazem a opção por essa área da ciência ainda precisam conviver com discursos que as naturalizam em uma falta de condições cognitivas para cursar a Física, que é considerada uma ciência hard. Para Schiebinger (2001, p. 298), "a dureza da ciência - no que ela estuda, como ela o estuda, e o grau de dificuldade a ela atribuída - é correlata ao prestígio, aos subsídios e, negativamente, ao número de mulheres no campo". 
Silva, F. F.; Ribeiro, P. R. C.

Nesses ambientes predominantemente masculinos, as mulheres acabam desenvolvendo determinadas "estratégias" ${ }^{5}$ de sobrevivência, sobretudo para se protegerem das situações de violência e assédio. Sobre essa questão, Lili comenta:

O meu marido é meu namorado desde que eu fui pra [cidade] com 17 anos. Desde o primeiro dia de aula en apareci com ele. Era uma pessoa muito presente na minha vida. Então os meus colegas sempre tiveram essa imagem de que a Lili tinha um namorado sério, um namorado fixo, isso era uma coisa que meio que me protegia dessa coisa de assédio que existe por tu ser a única mulher no meio de um bando de homens. Além disso, eu não pintava a unba, não fazia cabelo. Eu nunca fui muito perua, agora que en sou mais perua, mas, dentro da Engenharia Elétrica, se eu fosse muito arrumada eu chamava muita atenção por ser a única mulher. Então eu tinha esse cuidado de não chamar muita atenção e ter um namorado fixo. (Lili)

Nessa narrativa, percebemos que andar sempre com o namorado, torná-lo uma figura presente na sua vida, não utilizar determinados marcadores femininos para não chamar a atenção dos colegas constituíam as estratégias utilizadas pela Lili para se proteger e ser respeitada pelos colegas. Para adaptar-se ao ambiente masculino e aumentar a sua credibilidade como estudante de Engenharia, ela abandonou determinados adornos e comportamentos ligados à identidade feminina, tornando-se de alguma forma "invisível" como mulher. Sobre essa questão, Schiebinger (2001, p. 152) argumenta que "O abandono dos atavios da 'feminilidade' não só é geralmente necessário para uma mulher ser levada a sério como cientista, mas é com frequência importante também para evitar atenção indesejável à sua sexualidade". Desse modo, a narrativa da Lili nos leva a pensar que determinados adornos e comportamentos "femininos" não só devem ser evitados para que as mulheres não chamem a atenção dos homens, evitando, com isso, serem assediadas, como, também, para que se tornem mais próximas dos homens e da seriedade da ciência. Conforme destaca Keller (2006, p. 32), "as mulheres cientistas sofrem pressões específicas para abrir mão de quaisquer valores tradicionais que possam ter absorvido enquanto mulheres - se não por outra razão, simplesmente para provar sua legitimidade como cientistas.".

Estabelecer conexões com a perspectiva foucaultiana de poder tem nos possibilitado pensar na multiplicidade de mecanismos de poder e resistência que funcionam no corpo social. A partir de Foucault (2006), pensamos o poder como uma estratégia, exercício que se constitui por tática, técnicas, resistências. Para Foucault (1995, p. 248), "não há relação de poder sem resistência, sem escapatória ou fuga, sem inversão eventual; toda relação de poder implica, então, pelo menos de modo virtual, uma estratégia de luta".

Nessa perspectiva, as narrativas apresentadas criam condições para pensarmos nas distintas formas de viver das mulheres na ciência, que exigem movimentos de resistência e de luta num contexto masculino. Assim, é fundamental compreender que as relações entre ho-

${ }^{5}$ Utilizamos "estratégia" como "mecanismos utilizados nas relações de poder" (FOULCAULT, 1995, p. 248), como exercício do poder. 
mens e mulheres na ciência se constituem por relações de poder que expressam e determinam valores, interesses, necessidades, desejos e representações sociais e culturais, que, muitas vezes, podem produzir preconceitos de gênero. Se entendermos que essas relações são construídas, elas podem, então, ser modificadas. Precisamos romper com a lógica binária e, de certo modo, "perversa" do preconceito de gênero, problematizando as relações que nos constituem como sujeitos de determinada história e cultura.

\section{Conciliando identidades: mulher, mãe, esposa, cientista...}

$\mathrm{Na}$ construção das suas carreiras, as mulheres também se defrontam com a necessidade de conciliarem as responsabilidades familiares com as exigências da profissão.

A profissão científica tornou-se, sem dúvida, um tipo muito particular de profissão "moderna", a qual possui uma cultura específica no processo de aquisição dos requisitos básicos para pertencer à comunidade científica. Tal cultura está centrada em valores masculinos que se impõem, em certa medida, como obstáculos para a efetiva participação das mulheres na ciência. Velho (2006) destaca que as mulheres, para seguirem na carreira científica e serem bem-sucedidas profissionalmente, necessitam construir a sua identidade profissional de acordo com o "modelo masculino", que, conforme já anunciamos neste texto, envolve compromissos em tempo integral com o trabalho científico, relações competitivas e produtivas. Nesse contexto, a produtividade científica, mensurada pelo número de publicações em artigos e livros nacionais e internacionais, coloca o(a) pesquisador(a) frente ao desafio de ser produtivo(a). Sobre essa questão Mariana comenta:

Tem muita competitividade. Tem gente que fica horas olhando os curriculos dos outros, enfim, realmente não é o meu caso. Eu gostaria de publicar mais. Eu acho que en teria capacidade se eu priorizasse isso, então vou ficar até não sei que horas estudando, escrevendo, mas acabei entendendo pra mim que isso não é a coisa mais importante. Mas existe uma competitividade, a gente compete por bolsa, compete por projeto. E na verdade a tua moeda cientifica é trabalho publicado. O negócio é ter currículo. Têm mulheres, algumas eu conbeço, que elas são altamente produtivas, são respeitadas pela sua produtividade, pela sua capacidade, muitas que hoje inclusive estão ocupando cargos importantes e que são extremamente eficažes, mas justamente essas não têm filhos, essas que eu tô me lembrando agora não têm filhos. Então se enfurnam de cabeça dentro do laboratório, e realmente é óbvio que a produção cresce. (Mariana)

Nessa narrativa fica evidente que muitas mulheres, para serem bem-sucedidas profissionalmente, acabam adaptando-se às regras vigentes na ciência que pressupõem uma valorização da publicação, já que "a moeda científica é trabalho publicado". A lógica de uma carreira científica bem-sucedida sustenta-se na equação: pesquisa + publicação $=$ recursos. Nesse sentido, os membros da comunidade científica necessitam de uma expressiva produção para que possam concorrer de forma "igualitária" por bolsas, projetos, posições, recursos etc. Nas palavras da Mariana: "o negócio é ter currículo". E um "bom" currículo implica reconhecimento, respeito pelos pares. A necessidade de cientistas, mulheres e homens, adqui- 
Silva, F. F.; Ribeiro, P. R. C.

rirem reconhecimento na ciência estimula a "corrida" pelo Currículo Lattes, constituindo o campo científico como um espaço de disputas teóricas, rivalidades, cobranças, reproduzindo o sistema cultural que, geralmente, é compartilhado pelos sujeitos que deste campo participam. Segundo Sguissardi (2010), o "produtivismo acadêmico" alimenta-se do e no processo de competição que se dá interuniversidades, interprogramas de pós-graduação e entre docentes/pesquisadores, gerado por agências de fomento à pesquisa que adotam o Currículo Lattes como instrumento indicador da produtividade. Nesse contexto, o importante é ser produtivo. Para tanto, é necessário dedicação, "viver" para a ciência, priorizar a produção científica. O resultado de tudo isso é o mérito, reconhecimento, respeito. Na lógica "meritocrática", cada sujeito está na posição que merece, devido ao esforço, dedicação e capacidade individual, como se a ciência fosse resultado de "saberes descorporificados", sem gênero, etnia/raça, classe social, país de origem etc., em oposição aos "saberes corporificados e localizados" que propõe Haraway (1995).

Nessa perspectiva, é importante considerar que a entrada das mulheres na ciência, esfera pública, necessariamente, não as tem desobrigado das responsabilidades com o cuidado da casa e filhos, já que persiste a tradicional divisão sexual do trabalho. Desse modo, a mulher-mãe-pesquisadora, se depara com uma jornada excessiva, na qual precisa dar conta das exigências da vida acadêmica e das responsabilidades familiares.

Eu acho que ainda hoje é exigido bem mais da mulher, porque que, além dessa questão profissional, sempre tem a questão, especialmente pra quem tem família, a questão do lar, de filhos. Eu acho que querendo ou não é exigido mais dela ou ela acaba fazendo mais coisas, fazer almoço, fazer janta, gerenciar colégio de filho, além do seu trabalho. Talvez isso favoreça a questão de trabalhar com múltiplas coisas ao mesmo tempo. Porque ela gerencia isso e acaba gerenciando o trabalho. Agora, assim como tudo pra fazer bem as coisas, eu acho que tu tens que ter um limite, só publicar tendo familia não tem como. Alguma coisa realmente vai sair prejudicada. (Mariana)

Além das questões impostas pela divisão sexual do trabalho, que implica a dupla jornada de atividades que caracterizam o cotidiano de muitas mulheres, a narrativa da Mariana nos leva a pensar na representação de uma "supermulher", que consegue gerenciar a família e a vida acadêmica, mesmo que, para isso, precise enfrentar múltiplas jornadas de trabalho. Por outro lado, a narrativa da Mariana nos leva a pensar na difícil tarefa de conciliar carreira e família, especialmente quando se tem filhos, já que a escolha pela maternidade pode significar, entre outras coisas, uma diminuição da produtividade para algumas mulheres.

Assim, na construção das suas trajetórias na ciência, as mulheres entrevistadas foram levadas a fazer escolhas em função da carreira que, no entendimento delas, resultou em um prejuízo para a maternidade, filhos, família.

Enquanto eles eram pequenininhos eu contava história na hora de dormir, aquela coisa toda, mas depois, quando eu comecei a entrar firme naquele negócio de querer ampliar a pesquisa com [objeto de estudo] no Brasil e até na América do Sul, en comecei a viajar muito e eu acho que eu fiz falta em casa. Eu acho que 
Trajetórias de mulheres na ciência: ...

quem saiu prejudicada nessa vida foi a maternidade e não a pesquisa. Eu acho que eu priorizei a pesquisa e eles se queixam disso. (Carolina)

Tu tá falando e tu tá me fazendo pensar, a [nome] que é um congresso importantíssimo na minha área, sempre acontece em final de agosto, e eu tenho uma filha que faz aniversário dia 30 de agosto. E ela diæ: "Graças a [nome] foram poucos os aniversários que tu tava junto comigo". Eu ficava muito triste com isso, quando eu podia en saía antes, mas às vezes eu tinha a apresentação de trabalho, on a apresentação do aluno que me impedia de sair antes. Às vezes realmente eu ficava ausente de uma data que pra mim é extremamente importante. (Bildi)

Nessas narrativas, percebemos um tom de remorso e culpa por se dedicarem mais à carreira em detrimento dos filhos, a partir daquilo que consideravam como sendo responsabilidades da "mulher-mãe", gerando um conflito de identidades. Sobre essa questão, Woodward (2005, p. 31-32) destaca que "podemos viver, em nossas vidas pessoais, tensões entre nossas diferentes identidades quando aquilo que é exigido por uma identidade interfere com as exigências de uma outra.". Social e culturalmente, instituem-se os significados do "sermãe", define-se o que se espera para uma "mulher-mãe", repetem-se, incessantemente, o que a mãe é ou deve ser. Zelar pelo bem-estar e educação dos filhos, acompanhar de perto o crescimento deles, estar presente em datas importantes são algumas das atribuições da mãe. Tais significados produzidos por diversas instâncias sociais - família, escola, mídia -, e campos de saberes - Medicina, Psicologia, Biologia, Educação -, ao interpelarem as mulheres, ensinam maneiras de ser e agir como mães de determinados tipos. Cabe destacar que, embora os significados atribuídos à maternidade e ao cuidado dos filhos pareçam universais e fixos, eles são datados, variam de acordo com os contextos históricos, culturais e sociais. Portanto, a maneira como as mulheres, as famílias e as sociedades percebem a relação mãe-filho nem sempre foi a mesma.

Não pretendemos, nos limites deste texto, aprofundar historicamente as concepções sobre a maternidade e o papel das mulheres. No entanto, convém sublinhar que houve épocas em que a criança tinha pouca importância, era considerada como um "estorvo", em função disso, era comum as crianças de famílias urbanas ricas serem entregues a amas de leite e criadas por algum tempo (BADINTER, 1985). Não significa dizer que não existiam sentimentos entre pais e filhos, mas a relação era de outra ordem. A maternidade foi ressignificada no final do século XVIII, quando as mulheres da aristocracia foram incentivadas a retornar ao lar, a cuidar de seus filhos e a amamentá-los (BADINTER, 1985). A criança passou a ocupar lugar central na família e na vida da mulher. Reforçou-se o pressuposto de que a mulher que tem um filho deve arcar com a responsabilidade do cuidado e amor com a criança. Além disso, se, por um lado, a nova relação mãe-filho conferiu às mulheres outra representação na família e na sociedade, afastar-se dela, negligenciar as novas responsabilidades da mulher-mãe trazia enorme culpa, uma vez que contrariava a "natureza feminina" (BADINTER, 1985).

A força dos discursos que posicionam a mulher como a principal responsável pelo cuidado dos filhos e da casa tem levado muitas mulheres a optar por jornadas parciais de trabalho ou, até mesmo, por interrupções na vida profissional (AQUINO, 2006). Sobre essa questão, Carolina contou que mudou sua trajetória profissional para acompanhar o marido 
Silva, F. F.; Ribeiro, P. R. C.

que foi fazer mestrado em outro país, mas que ela continuou trabalhando como pesquisadora. Contudo, quando retornou, estava grávida, e só voltou a trabalhar depois de três anos. Além disso, Carolina, ao narrar as dificuldades em conciliar trabalho e vida familiar, contou que, em função da casa e da família, por um longo período trabalhou apenas vinte horas.

É muito difícil, de fato não é fácil. Agora pra mim até certo ponto facilitou o fato de poder trabalhar 40 horas ou 20, e eu em função da casa e da família fiz. 20 horas por muito tempo. (Carolina)

Quando questionada se a responsabilidade dos filhos é da mulher, Carolina respondeu:

É por uma questão atávica, de que em qualquer espécie quem reproduz é o responsável por isso, quem carrega os filhos é aquele que tem que carregar os filhos, não tem choro. Se a mulher resolve desempenhar o outro papel paga um preço por isso, e os filhos pagam também, eu acho. (Carolina)

Essa narrativa cria condições para problematizarmos a forma como a Carolina naturaliza a maternidade ao percebê-la como uma função/obrigação inata da mulher, que, portanto, tem como pressuposto uma matriz biológica. A maternidade, como uma experiência puramente biológica, um destino de toda mulher, há muito tempo foi refutada pelas feministas, que procuraram mostrar a maternidade como uma construção social, cultural e histórica, que designava o lugar da mulher na familia e na sociedade (SCAVONE, 2001). Apesar dos esforços feministas em apontar o caráter essencialista e determinista presente nas concepções biologizantes da maternidade, tais entendimentos ainda persistem nas formas de compreender a relação mãe e filho na atualidade, sendo produzidos e reproduzidos através de diferentes instâncias e artefatos culturais. Não se trata de desconsiderar os aspectos biológicos da reprodução, mesmo com a emergência das tecnologias reprodutivas - técnicas contraceptivas e conceptivas (SCAVONE, 2002) -, mas, sim, de compreender que não é a questão biológica da reprodução que determina o papel das mulheres como mães, mas as relações de gênero atravessadas pelo poder/saber que atribuem um significado social à maternidade. Nessa perspectiva, é importante pensar o corpo da mulher como histórica e socialmente atravessado por discursos médicos, biológicos, políticos e econômicos que naturalizaram a maternidade e os cuidados maternos.

A representação da maternidade que posiciona a mulher como a principal responsável pelo cuidado dos filhos influenciou os projetos de vida de algumas das entrevistadas, que optaram por adiar a maternidade ou, definitivamente, recusá-la em função da carreira.

Eu não teria muitos filhos, porque a gente trabalha demais. Então, se tu trabalhas muito, tu não tem como ter muitos filhos, porque tu não tens tempo pra dar atenção pra eles. Foi uma opșão minha, mas eu teria dois, eu acho, mas eu não queria ter nenhum. Eu evitei em ter filho até o último instante, tive filho sem planejar porque en achava que ia atrapalhar a minha carreira. (Lili) 
Eu me arrependo de ter adiado [a maternidade], porque quando eu me dei conta eu tinha um problema que era grave. Eu tenho ovário policístico. O meu caso não é simples, mas poderia ter havido alguma solução se eu tivesse começado mais cedo. Isso eu acho que é uma coisa absurda na ciência, é muito mais complicado tu resolver ter filhos no meio da tua trajetória de formação. Essa trajetória acaba sendo muito longa e tu acabas saindo do periodo ideal de ter filho. Sempre achei meio absurdo tu ter que optar por não ter filhos. Ou tu é cientista ou tu tem filho. Se tu resolver fazer as duas coisas tu vai sofrer o dobro. (Sianiak)

As histórias narradas por Lili e Sianiak nos induzem a pensar que a necessidade de submissão ao "modelo masculino de ciência" acompanhou suas trajetórias acadêmicas, levando-as a adiar a experiência da maternidade, com consequências para Sianiak, que contou que gostaria de ter realizado a maternidade. A mulher que decide seguir uma carreira científica poderá pensar duas vezes em escolher ser mãe ou ser cientista, em função da necessidade de conciliar a carreira com a maternidade. Contudo, ousamos dizer que os homens, dificilmente, irão se confrontar com essa questão. Conforme destaca Velho (2006, p. xvii), "apenas em um 'modelo masculino' de carreira acadêmica a escolha da estudante entre ser mãe ou pesquisadora se coloca".

Para finalizar, destacamos a narrativa da Salamandra, ao argumentar que fez a opção por não ter filhos em função da carreira.

Não tenho filhos e sou consciente de que ter filhos requer uma dedicação imensa. Nos meus relacionamentos afetivos sempre deixei claro que o meu trabalho vinha em primeiro lugar. Meus pais são o unico vínculo que mantenho acima do trabalho. [...] Não ter filhos foi uma opção. (Salamandra)

Ser mãe e cientista requer um equilibrio entre a vida profissional e familiar que certamente não se coloca como tarefa fácil, sobretudo quando as atividades científicas pressupõem produtividade e competitividade. Nessa perspectiva, ser mãe ou ser cientista, ter ou não filhos, quantos, quando, quem cuida dos filhos etc. foram questões que acompanharam a trajetória acadêmica e profissional das entrevistadas e as levaram a fazer determinadas escolhas. Para além dos motivos que fizeram as entrevistadas adiantarem, adiarem ou recusarem a maternidade, certamente, esteve em questão a representação social da maternidade, que posiciona a mulher como a principal responsável pelo cuidado dos filhos.

\section{Considerações finais}

Analisar a trajetória acadêmica e profissional das entrevistadas implica compreender que ela é construída em um ambiente regido por valores e padrões masculinos que restringem, dificultam e direcionam a participação das mulheres na ciência. Desse modo, percebemos que as entrevistadas foram, de alguma forma, interpeladas pelo "modelo masculino" de pensar e fazer ciência, não apenas para serem consideradas cientistas, mas, também, para serem bem-sucedidas na profissão. 
Silva, F. F.; Ribeiro, P. R. C.

$\mathrm{Na}$ análise das narrativas, evidenciamos que as entrevistadas se defrontaram com um conjunto de "barreiras" para seguir a carreira científica, que se refere: à dupla jornada de trabalho, à maternidade, à produtividade em pesquisa, à competição, ao preconceito e discriminação de gênero.

Nesse sentido, entendemos que conjugar ciência e feminino não se configura como uma tarefa fácil, já que são dois mundos estruturados na dicotomia do público/privado que define os espaços sociais a serem ocupados pelos sujeitos, onde o mundo público é destinado ao masculino e o privado ao feminino. É preciso romper com essa lógica binária que estrutura o pensamento moderno, "revertendo e deslocando sua construção hierárquica, em vez de aceitá-la como real ou autoevidente ou como fazendo parte da natureza das coisas" (SCOTT, 1995, p. 84). Desconstruir a lógica binária dos gêneros implica problematizar a oposição hierárquica existente entre eles, na qual o masculino é tomado como referência, como, também, compreender o caráter construído, fragmentado, contingente e plural das identidades, afinal, não existe a mulher como categoria universal e fixa, mas várias e diferentes mulheres, que aprendem a ser, pensar, agir e se reconhecer de determinado jeito de acordo com os contextos sociais, culturais e históricos em que estão inseridas. Portanto, as análises que realizamos se configuram como contingentes, provisórias, limitadas às trajetórias vividas pelas entrevistadas.

Para finalizar, defendemos a necessidade de introduzir, na ciência, uma perspectiva de gênero. Não se trata de criar uma "ciência feminista" especial e esotérica, conforme argumenta Schiebinger (2001, p. 31), mas sim, "incorporar uma consciência crítica de gênero na formação básica de jovens cientistas e no mundo rotineiro da ciência.". É preciso problematizar o pressuposto de que a ciência é neutra com relação às questões de gênero, revelando que os valores e as características socialmente atribuídos às mulheres são desvalorizados na produção do conhecimento, e que desigualdades de gênero perpassam o campo científico, por exemplo, no que se refere: à sub-representação feminina em determinadas áreas da ciência, a ocupação de cargos de direção e o recebimento de bolsas PQ do CNPq, entre outros aspectos.

\section{Referências}

AQUINO, E. M. L. Gênero e ciência no Brasil: contribuições para pensar a ação política na busca da equidade. In: BRASIL. Secretaria Especial de Políticas para as Mulheres. Encontro nacional pensando gênero e ciência: núcleos e grupos de pesquisas. Brasília, 2006. p. 11-18. Disponível em: <http://www.livrosgratis.com.br/arquivos_livros/br000014.pdf>. Acesso em: 30 abr. 2014.

BADINTER, E. Um amor conquistado: o mito do amor materno. Rio de Janeiro: Nova Fronteira, 1985.

BOURDIEU, P. A ilusão biográfica. In: AMADO, J.; FERREIRA, M. M. (Org.). Usos \& abusos da história oral. 8. ed. Rio de Janeiro: Editora FGV, 2006. p.183-191.

BRASIL. Conselho Nacional de Desenvolvimento Científico e Tecnológico. Séries históricas até 2012: quantitativos de bolsas por sexo. Brasília, 2012. Disponível em: <http://www.cnpq.br/series-historicas>. Acesso em: 30 abr. 2014.

CABRAL, C. O conhecimento dialogicamente situado: histórias de vida, valores humanistas e consciência crítica de professoras do Centro Tecnológico da UFSC. 2006. 206 f. Tese (Doutorado em Educação Científica e Tecnológica) - Universidade Federal de Santa Catarina, Florianópolis, 2006. 
CONNELLY, M.; CLANDININ, J. Relatos de experiencia e investigación narrativa. In: LARROSA, J. et al. Déjame que te cuente. Barcelona: Laertes, 1995. p. 11-59.

ESTÉBANEZ, M. E. La mujer y la ciencia iberoamericana. In: BIELLI, A. et al. Proyecto iberoamericano de ciencia, tecnología y género - GENTEC - UNESCO. S. 1.: OEI: Unesco, 2004. p. 1-39. Disponível em: <http://www.comunicacion.amc.edu.mx/comunicacion/docs/ Reporte_Final\%20GENTEC.pd>. Acesso em: 30 abr. 2014.

FELÍCIO, J. R. D. A política das agências de fomento na promoção da participação das mulheres na pesquisa. In: ENCONTRO NACIONAL DE NÚCLEOS E GRUPOS DE PESQUISA PENSANDO GÊNERO E CIÊNCIAS, 2., 2010, Brasília. Brasília: Secretaria Especial de Políticas para as Mulheres, 2010. p. 45-52. Disponível em: <http://www.spm.gov.br/publicacoes-teste/publicacoes/2010/ spm-nucleos-web.pdf > . Acesso em: 30 abr. 2014.

FOUCAULT, M. O sujeito e o poder. In: DREYFUS, H. L.; RABINOW, P. Michel Foucault - uma trajetória filosófica: para além do estruturalismo e da hermenêutica. Rio de Janeiro: Forense Universitária, 1995. p. 231-249.

Vigiar e punir: nascimento da prisão. 31. ed. Petrópolis: Vozes, 2006.

. A arqueologia do saber. 7. ed. Rio de Janeiro: Forense Universitária, 2008.

HARAWAY, D. Saberes localizados: a questão da ciência para o feminismo e o privilégio da perspectiva parcial. Cadernos Pagu, Campinas, n. 5, p. 7-41, 1995.

HENNING, P. C. Efeitos de sentido em discursos educacionais contemporâneos: produção de saber e moral nas ciências humanas. 2008. 282 f. Tese (Doutorado em Educação) - Universidade do Vale do Rio dos Sinos, São Leopoldo, 2008.

KELLER, E. F. Qual foi o impacto do feminismo na ciência? Cadernos Pagu, Campinas, n. 27, p. 13-34, jul./dez. 2006.

LARROSA, J. Narrativa, identidad y desidentificación. In: La experiencia de la lectura. Barcelona: Laertes, 1996. p. 461-482.

. Notas sobre narrativa e identidad. In: ABRAHÃO, M. H. B. (Org.). A aventura (auto)biográfica: teoria e empiria. Porto Alegre: EDIPUCRS, 2004. p. 11-22.

LIMA, B. S. Teto de vidro ou labirinto de cristal?: as margens femininas das ciências. 2008. 133 f. Dissertação (Mestrado em História) - Universidade de Brasília, Brasília, 2008.

LOURO, G. L. Gênero, sexualidade e educação: uma perspectiva pós-estruturalista. Petrópolis: Vozes, 2004.

LÖWY, I. Ciências e gênero. In: HIRATA, H. et al. (Org.). Dicionário crítico do feminismo. São Paulo: Editora UNESP, 2009. p. 40-44.

SCAVONE, L. A maternidade e o feminismo: diálogos com as ciências sociais. Cadernos Pagu, Campinas, n. 16, p.137-150, 2001.

. Impactos das novas tecnologias reprodutivas. In: COSTA, A. A. A.; SARDENBERG, C. M. B. (Org.). Feminismo, ciência e tecnologia. Salvador: Universidade Federal da Bahia, 2002. p. 141-149.

SCHIEBINGER, L. O feminismo mudou a ciência? São Paulo: EDUSC, 2001.

SCOTT, J. W. O enigma da igualdade. Estudos Feministas, Florianópolis, v. 13, n. 1, p. 11-30, jan./ abr. 2005. 
Silva, F. F.; Ribeiro, P. R. C.

. Experiência. In: SILVA, A. L.; LAGO, M. C. S.; RAMOS, T. R. O. (Org.). Falas de gênero: teorias, análises, leituras. Florianópolis: Mulheres, 1999. p. 21-55.

Gênero: uma categoria útil de análise histórica. Educação \& Realidade, Porto Alegre, v. 20, n. 2, p. 71-99, 1995.

SGUISSARDI, V. Produtivismo acadêmico. In: OLIVEIRA, D. A.; DUARTE, A. M. C.; VIEIRA, L. M. F. (Org.). Dicionário de trabalho, profissão e condição docente. Belo Horizonte: Universidade Federal de Minas Gerais, 2010.

SILVA, T. T. da. A produção social da identidade e da diferença. In: SILVA, T. T. da (Org.). Identidade e diferença: a perspectiva dos estudos culturais. 4. ed. Petrópolis: Vozes, 2005. p. 73-102.

SILVEIRA, R. M. H. A entrevista na pesquisa em educação: uma arena de significados. In: COSTA, M. V. (Org.). Caminhos investigativos II: outros modos de pensar e fazer pesquisa em educação. 2. ed. Rio de Janeiro: Lamparina, 2007. p. 117-138.

SOUZA, A. M. F. L. As armas de marte no espelho de vênus: a marca de gênero em Ciências Biológicas. 2003. 216 f. Tese (Doutorado em Educação) - Faculdade de Educação, Universidade Federal da Bahia, Salvador, 2003.

TABAK, F. Estudos substantivos sobre mulher e ciências no Brasil. In: COSTA, A. A. A.; SARDENBERG, C. M. B. (Org.). Feminismo, ciência e tecnologia. Salvador: Universidade Federal da Bahia, 2002. p. 39-49.

VELHO, L. Prefácio. In: SANTOS, L. W.; ICHIKAWA, E. Y.; CARGANO, D. F. (Org.). Ciência, tecnologia e gênero: desvelando o feminino na construção do conhecimento. Londrina: IAPAR, 2006. p. xiii-xviii.

WOODWARD, K. Identidade e diferença: uma introdução teórica e conceitual. In: SILVA, T. T. da (Org.). Identidade e diferença: a perspectiva dos estudos culturais. 4. ed. Petrópolis: Vozes, 2005. p. 7-72.

Artigo recebido em 15/06/13. Aceito em 08/01/14. 